\title{
Influence of Freeze-Thaw Cycles on the Strength and Leaching Characteristics of Chromium-Contaminated Soil Repaired by Reduction-Solidification/Stabilization
}

\author{
Xilin Li ${ }^{1, ~ *, ~ Z h o n g k a i ~ T o n g ~}{ }^{1}$, Ling Liu ${ }^{1}$, Xiaowan $\mathrm{Yu}^{1}$ and Dan Meng ${ }^{2}$ \\ ${ }^{l}$ School of Civil Engineering, Liaoning Technical University, Fuxin 123000, Liaoning, China \\ ${ }^{2}$ School of Built Environment, University of New South Wales, Sydney 2052, NSW, Australia
}

Received 10 October 2020; Accepted 27 December 2020

\begin{abstract}
The key to the application of chromium-contaminated soil as roadbed fillings and building materials after remediation is to determine the stability of the soil. However, there are some problems with the single remediation technology such as poor repaired effects and instability under extreme weather conditions. To resolve this problem, the composite preparation (calcium polysulfide, synthetic zeolite from fly ash and cement) was used for reduction-solidification/ stabilization. The effects of the zeolite contents, cement contents, initial chromium concentrations and numbers of freezethaw cycles on the freeze-thaw cycles stability were explored. The freeze-thaw damage mechanism under different numbers of freeze-thaw cycles was analyzed by scanning electron microscopy (SEM) and X-ray diffraction (XRD). Results demonstrate that during freeze-thaw cycles, the increase in cement contents is beneficial to increase the unconfined compressive strength (UCS) of chromium-contaminated soil after remediation, but it cannot meet the leaching requirement of total chromium in high-concentrations chromium-contaminated soil. The increase in zeolite contents has little effect on the UCS, but it does reduce the leaching of total chromium. Changes in the pollutants concentrations can retard the hydration reaction in the soil structure to different degrees. In the initial freeze-thaw cycles, the UCS increases slightly, and the leaching concentrations of pollutants decrease. Then, the UCS decreases gradually, while the leaching concentrations of pollutants increase gradually. After the freeze-thaw cycles, the chromiumcontaminated soil after combined remediation can maintain a low leaching rate and show a little strength loss, which means it can be applied as roadbed fillings and building materials. Conclusions provide a significant reference for the engineering application of chromium-contaminated soil after remediation.
\end{abstract}

Keywords: Chromium-contaminated soil, Freeze-thaw cycles, Combined remediation, Stability, Synthetic zeolite from fly ash

\section{Introduction}

Soil is a common constituent material of building foundation and roadbed, and its physical, mechanical and chemical properties are important. In recent years, heavy metal contaminated soil has become an important constraint for the use of soil as building foundation and roadbed. Contaminated soil can not only harm human health through food and skin contact, but also lead to engineering safety hazards due to the change of engineering characteristics [1]. As a kind of contaminated soil, chromium-contaminated soil has characteristics of strong toxicity, persistence, complexity and irreversibility, so its pollution remediation has become a quite urgent problem. The toxicity of chromiumcontaminated soil mainly comes from $\mathrm{Cr}$ (VI) and $\mathrm{Cr}$ (III). Compounds containing Cr (VI) have strong carcinogenicity and are ranked 6th on the US Environmental Protection Agency's (EPA) priority pollutant list. The toxicity of Cr (III) is generally considered to be lower than that of $\mathrm{Cr}$ (VI), which is approximately $1 / 100$ of $\mathrm{Cr}(\mathrm{VI})$. However, some studies indicate that $\mathrm{Cr}$ (III) has a stronger inhibitory effect on soil urease than $\mathrm{Cr}$ (VI) at the same concentrations [2]. In addition, $\mathrm{Cr}$ (III) can be converted to $\mathrm{Cr}$ (VI) under certain conditions. So the effects of Cr (III) are also worthy of attention [3]. The presence of high concentrations of heavy

\footnotetext{
*E-mail address: lixilin@Intu.edu.cn

ISSN: 1791-2377 @ 2021 School of Science, IHU. All rights reserved. doi:10.25103/jestr. 141.06
}

metal pollutants can significantly change the basic physical and mechanical properties of soil, reduce the unconfined compressive strength (UCS) and bearing capacity, and may cause safety issues in many cases [4]. Therefore, it is necessary to take corresponding remediation measures to meet the requirements of human beings for living or to make the repaired contaminated soil meet the requirements of roadbed filling and building materials, so as to realize the resource remediation of waste recycling.

To reduce the harm caused by heavy metal pollution, some effective remediation technologies of heavy metalcontaminated soil have been researched, mainly including solidification/stabilization, chemical reduction, chemical cleaning, bioremediation, and electric remediation [5-7]. In previous studies, solidification/stabilization method and chemical reduction method have been applied. However, the long-term effect of the single remediation method is not ideal to high-concentrations chromium-contaminated soil containing $\mathrm{Cr}$ (VI) and $\mathrm{Cr}$ (III). Since a single solidification/ stabilization process can increase the capacity after solidification. Once the solidified body is broken, $\mathrm{Cr}$ (VI) can easily re-enter the environment due to the strong migration ability [8]. Moreover, in the process of chemical reduction, the reducing agent has poor contact with the soil. Adding a small amount of the reducing agent results in incomplete reduction, whereas a large amount may cause the secondary pollution [9]. Therefore, a method of combining the chemical reduction with solidification/stabilization is 
considered, which may be of great significance to solve the remediation problem of chromium-contaminated soil completely.

To resolve the problem associated with highconcentrations chromium-contaminated soil, we proposed a new combined remediation technology of reductionadsorption-solidification [10]. Firstly, the reducing agent calcium polysulfide was used to reduce highly toxic $\mathrm{Cr}$ (VI) to less toxic $\mathrm{Cr}$ (III). Then, synthetic zeolite from fly ash was used to adsorb high concentrations of $\mathrm{Cr}$ (III) reduced from $\mathrm{Cr}$ (VI) and existing in the original soil. Finally, the cement was used for solidification. The repaired soil can be used as roadbed filling, which is expected to provide a new opinion for the application of chromium-contaminated soil.

\section{State of the art}

There are many seasonal and short-period freeze-thaw effects in some regions of the world. Extreme freeze-thaw weather conditions, such as nonseasonal alternating freezing and increased temperature gaps between day and night, have a significant impact on the durability of repaired heavy metal-contaminated soil. It is an issue worthy of attention whether the repaired chromium-contaminated soil can maintain long-term stability and the UCS can meet the requirements without secondary pollution. Many studies show that freeze-thaw cycles can destroy the internal structure of solidified soil, impact the mechanical properties, reduce the adsorption capacity of heavy metal ions in the soil, and increase the risk of heavy metal leaching [11-13]. Current researches have mainly evaluated the effects of freeze-thaw cycles on conventional solidified soil. Few researches have focused on solidified heavy metalcontaminated soil. Janoo et al. [14] conducted on-site monitoring and analysis of cement-improved soil under freeze-thaw cycles. The upper roadbed has a 50\% strength loss after freeze-thaw cycles. Shihata et al. [15] found that the UCS was an effective index for evaluating the freezethaw durability of cement soil. Yarbasi et al. [16] compared the UCS, bearing ratio, resonance tests and other parameters of three modified soils of lime, fly ash and cement after freeze-thaw cycles. The three modified soils have good freeze-thaw durability. Tiwari et al. [17] investigated the effects of adding silica fume to the soil on durability under freeze-thaw cycles. Adding silica fume can form hydrated gels, filling the soil pores. Muhannad et al. [18] researched the impact of freeze-thaw cycles on the behaviour of limestabilized fine-grained soils. Lime can increase the durability of cohesive roadbed soil exposed to freezing conditions. Baldovino et al. [19] discussed the effects of freeze-thaw cycles on cement-silt mixtures. Freeze-thaw cycles weaken the effect of hydration products on filling in soil pores and bonding soil particles. Aydin et al. [20] made use of waste calcitice marble powder (CMP) and dolomitic marble powder (DMP) to stabilize the fine-grained soils. CMP and DMP contribute the fine-grained soils to be more resistant to freeze-thaw cycles. Mukiza et al. [21] investigated the durability of roadbed materials prepared from red mud and flue gas desulfurization fly ash. Heavy metals are solidified below the minimum requirement during the freeze-thaw process, which indicates that these wastes are suitable for application in roadbed construction as a natural material replacement. Azarsa et al. [22] performed freeze-thaw tests on two types of geopolymer concrete (fly-ash based geopolymer concrete and bottom-ash based geopolymer concrete). Bottom-ash based geopolymer concrete has better freeze-thaw resistance than fly-ash geopolymer concrete, and the heavy metals can be effectively immobilized into the geopolymer paste. Yang et al. [23] studied the effects of freeze-thaw cycles on the UCS of Pb-contaminated soils. The soil structure is damaged by freeze-thaw effects, which is the main reason for the decrease in the UCS of soil specimens. Li et al. [24] researched the effects and action mechanism of freeze-thaw cycles on the engineering properties of $\mathrm{Pb}$-contaminated soil under different compaction degrees and different freeze-thaw times. The freeze-thaw cycles have a greater impact on the low-pressure solidity specimens than the high-pressure solidity specimens, while the impact on the micro-structure is also greater. Zhou et al. [25] simulated the effects of freeze-thaw cycles on the backfill soil through indoor tests. The freeze-thaw cycles reduce the UCS of heavy metal-contaminated soil solidified by cement. Different heavy metal ions have different effects on the UCS of solidified soil under freeze-thaw cycles. $\mathrm{Zn}^{2+}$ hinders the hydration reaction most significantly, followed by $\mathrm{Cu}^{2+}$ and then $\mathrm{Pb}^{2+}$. Wei et al. [26] used new phosphorus-containing materials (KMP) and cement (PC) to solidify and stabilize $\mathrm{Zn}$ - and $\mathrm{Pb}$-contaminated soils. The contaminated soil solidified by KMP and PC has better freeze-thaw resistance than untreated contaminated soil. Liu et al. [27] considered the UCS and micro-structural characteristics of $\mathrm{Zn}$-contaminated soil treated by cementsoda residue under freeze-thaw cycles. The freeze-thaw cycles can significantly reduce the UCS and destroy the crystalline structures of cement hydrates.

From the above researches, the previous researches mainly focus on the remediation materials and effects of $\mathrm{Zn}$-, $\mathrm{Pb}$-, and $\mathrm{Hg}$-contaminated soil and soil contaminated with other heavy metals. There are few studies on chromiumcontaminated soils, especially under the condition of extreme freeze-thaw climates coupled with changes in the chromium concentrations, and on the long-term stability of chromium-contaminated soils after remediation [28]. There are still many controversies regarding the microscopic mechanism of the reduction-solidification/stabilization combined remediation of chromium-contaminated soil during the freeze-thaw cycles, and there is no unified understanding.

In view of the shortcomings of existing researches, a combined remediation technology of reduction-solidification /stabilization using calcium polysulfide as a reducing agent, synthetic zeolite as an adsorbent, and cement as a solidified agent was proposed. The UCS and leaching characteristics of chromium-contaminated soil after remediation under freeze-thaw cycles were analyzed. The freeze-thaw cycles stability under different zeolite contents, cement contents, pollutant concentrations and freeze-thaw cycle numbers was investigated. Scanning electron microscopy (SEM) and Xray diffraction (XRD) were combined to study the microscopic change characteristics of the UCS and leaching of repaired chromium-contaminated soil under freeze-thaw cycles. The durability of repaired chromium-contaminated soil under freeze-thaw cycles was evaluated, and technical support was provided for the long-term stability of chromium-contaminated soil after remediation.

The rest of this study is organized as follows. Section 3 describes test materials and methodology. The UCS, leaching characteristics and microscopic characteristics of chromium contaminated soil under the influence of different factors are analyzed in Section 4. Section 5 summarizes this study and gives relevant conclusions. 


\section{Methodology}

\subsection{Test materials and specimen preparation}

\section{(1) Preparation of chromium-contaminated soil}

Sampling and determination results of the contaminated soil from Shenyang chromium contaminated site in China show that the $\mathrm{Cr}$ (VI) concentrations are $118.5-4965.0 \mathrm{mg} / \mathrm{kg}$, the $\mathrm{Cr}$ (III) concentrations are $138.2-5792.6 \mathrm{mg} / \mathrm{kg}$, the average $\mathrm{Cr}$ (VI) concentrations are $3000 \mathrm{mg} / \mathrm{kg}$, and the average $\mathrm{Cr}$ (III) concentrations are $3500 \mathrm{mg} / \mathrm{kg}$. Taking into account the heterogeneity and complexity of the original contaminated soil, the soil was taken from an uncontaminated area $2 \mathrm{~km}$ away from Shenyang chromium contaminated site. The soil is silty clay, the maximum dry density is $1.72 \mathrm{~g} / \mathrm{cm}^{3}$, and the optimal moisture contents are $22.0 \%$. Other physical properties and chemical components of the soil are shown in Tables 1 and 2. Debris was removed from the clay, passed through $2 \mathrm{~mm}$ sieve, and air dried. $\mathrm{K}_{2} \mathrm{CrO}_{4}$ and $\mathrm{Cr}\left(\mathrm{NO}_{3}\right)_{3}$ were used to prepare a solution with a certain mass concentrations and mixed with the sieved soil sample to produce contaminated soil with different chromium contents. The concentrations of Cr (VI) were respectively $1000 \mathrm{mg} / \mathrm{kg}$, $3000 \mathrm{mg} / \mathrm{kg}$ and $5000 \mathrm{mg} / \mathrm{kg}$, and the concentrations of $\mathrm{Cr}$ (III) were $7 / 6$ times the concentrations of $\mathrm{Cr}$ (VI). (All the chemicals used in the test were analytical pure.)

Table 1. Physical properties of silty clay

\begin{tabular}{c|c|c|c|c|c|c|c|c|c}
\hline $\begin{array}{c}\text { Inde } \\
\mathbf{x}\end{array}$ & $\begin{array}{c}\text { Natural density } \\
\left(\mathrm{g} / \mathrm{cm}^{3}\right)\end{array}$ & $\begin{array}{c}\text { Proportio } \\
\mathbf{n}\end{array}$ & $\begin{array}{c}\text { Saturation } \\
\mathbf{( \% )}\end{array}$ & $\begin{array}{c}\text { Liquid } \\
\text { limit (\%) }\end{array}$ & $\begin{array}{c}\text { Plastic } \\
\text { limit (\%) }\end{array}$ & $\begin{array}{c}\text { Plastic Limit } \\
\text { Index }\end{array}$ & $\begin{array}{c}\text { Void } \\
\text { ratio }\end{array}$ & \multicolumn{2}{|c|}{$\begin{array}{c}\text { Particle composition } \\
\text { (by weight)(\%) }\end{array}$} \\
\hline Value & 1.99 & 2.71 & 91.3 & 30.6 & 18.7 & 11.9 & 0.657 & 42 & Sand \\
\hline
\end{tabular}

Table 2. Chemical composition of silty clay (mass fraction) $(\%)$

\begin{tabular}{c|c|c|c|c|c|c|c|c|c|c}
\hline Index & Organic matter(g/kg) & $\mathbf{C E C}(\mathbf{c m o l} / \mathbf{k g})$ & $\mathrm{Al}_{2} \mathrm{O}_{3}$ & $\mathrm{Fe}_{2} \mathrm{O}_{3}$ & $\mathbf{M g O}$ & $\mathbf{C a O}$ & $\mathrm{Na}_{2} \mathrm{O}$ & $\mathrm{K}_{2} \mathrm{O}$ & $\mathbf{P}_{2} \mathrm{O}_{5}$ & $\mathrm{SiO}_{2}$ \\
\hline Value & 65.8 & 20.6 & 31.2 & 1.6 & 0.9 & 1.7 & 3.6 & 1.3 & 0.6 & 53.1 \\
\hline
\end{tabular}

Table 3. Chemical composition of cement and synthetic zeolite from fly ash (contents/\%)

\begin{tabular}{c|c|c|c|c|c|c|c|c|c|c}
\hline Chemical composition & $\mathrm{SiO}_{2}$ & $\mathrm{Al}_{2} \mathrm{O}_{3}$ & $\mathbf{C a O}$ & $\mathbf{M g O}$ & $\mathrm{Fe}_{2} \mathrm{O}_{3}$ & $\mathrm{~K}_{2} \mathrm{O}$ & $\mathrm{Na}_{2} \mathrm{O}$ & $\mathrm{TiO}_{2}$ & $\mathrm{SO}_{3}$ & Ignition \\
\hline Portland cement & 21.87 & 5.69 & 62.25 & 3.12 & 3.80 & 1.41 & 0.35 & - & 1.02 & 0.38 \\
Synthetic zeolite from fly ash & 50.29 & 14.17 & 3.42 & 1.96 & 7.23 & 1.05 & 20.88 & 0.55 & - & - \\
\hline
\end{tabular}

\section{(2) Composition and characterization of remediation materials}

The reducing agent $\mathrm{CaS}_{\mathrm{X}}$, with a volume fraction of $29 \%$, was purchased from China Lianyungang Lanxing Industrial Technology Co., Ltd. The main component $\mathrm{CaS}_{5}$ in the reagent was made of calcium oxide $(\mathrm{CaO})$ and sulfur $(\mathrm{S})$ under specific conditions, so it contained a small amount of impurities such as $\mathrm{CaO}$ and $\mathrm{S}$. Its XRD pattern is shown in Fig. 1. The test results show that it contains $\mathrm{Ca}(\mathrm{OH})_{2}$, which is due to the contact reaction between $\mathrm{CaO}$ and oxygen $\left(\mathrm{O}_{2}\right)$ in the environment during the drying process of $\mathrm{CaS}_{5}$ liquid. The chemical reaction equation is as follows:

$$
\mathrm{Cr}_{2} \mathrm{O}_{7}^{2-}+3 \mathrm{CaS}_{5}+8 \mathrm{H}^{+} \rightarrow 2 \mathrm{Cr}(\mathrm{OH})_{3}(\mathrm{~s})+15 \mathrm{~S}(\mathrm{~s})+3 \mathrm{Ca}^{2+}+\mathrm{H}_{2} \mathrm{O}
$$

The solidified agent is P.O42.5 Ordinary Portland cement (OPC), and the chemical composition is shown in Table 3 .

The adsorbent is the synthetic zeolite from fly ash, which is prepared by alkaline fusing and hydrothermal methods. The specific preparation method was as follows. Firstly, contents of $2 \mathrm{~mol} / \mathrm{L} \mathrm{NaOH}$ solution was mixed with fly ash at a liquid-solid ratio of $6.0 \mathrm{~mL} / \mathrm{g}$, and then it was put into a crucible and heated in a muffle furnace at $500{ }^{\circ} \mathrm{C}$ for $3 \mathrm{~h}$. The sample was taken out and ground into powder to prepare alkali fusion fly ash clinker. Next, distilled water was added to the fly ash clinker at a solid-liquid ratio of $1: 10$, and the reaction temperature was controlled to $90{ }^{\circ} \mathrm{C}$. The clinker was stirred with a magnetic stirrer at a constant speed of $200 \mathrm{r} / \mathrm{min}$ for $2 \mathrm{~h}$. Then, the mixture was put in the hydrothermal reactor, placed in an oven at $105{ }^{\circ} \mathrm{C}$ to crystallize for $9 \mathrm{~h}$. Finally, it was washed with distilled water and $95 \%$ ethanol at a $\mathrm{pH}$ of $7-9$, and dried and ground to obtain synthetic zeolite powder. Its chemical composition is shown in Table 3. The SEM images of fly ash and synthetic zeolite from fly ash are shown in Fig. 2, and the XRD patterns are shown in Fig. 3.

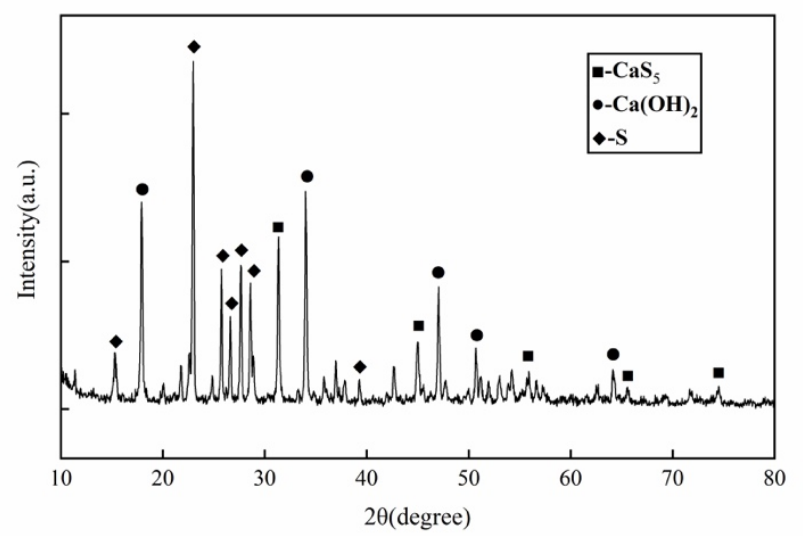

Fig. 1. XRD pattern of calcium polysulfide before reaction

Fig. 2 shows that the surface structure of fly ash is relatively smooth with a spherical glass body. However, the surface structure of the synthetic zeolite is no longer smooth, more pores are formed, the shape becomes extremely irregular, the spherical glass body disappears, and a crystal structure appears, resulting in a significant increase in its surface area, which is beneficial to improving its adsorption performance.

Fig. 3 shows that quartz and mullite are the main crystal phases of fly ash, which results in relatively poor fly ash activity and low metal cation adsorption performance. The crystal phase of zeolite prepared by the alkali fusionhydrothermal method is complicated. It can be seen from Fig. 3 that the X-type zeolite phase $\left(\mathrm{K}_{86.5} \mathrm{Al}_{86.5} \mathrm{Si}_{105.5} \mathrm{O}_{384}\right)$ appears at $2 \theta$ of $7.1^{\circ}, 23.2^{\circ}$, and $27.4^{\circ}$. the ZSM-3-type zeolite phase $\left(\mathrm{Na}_{1.88} \mathrm{Al}_{2} \mathrm{Si}_{2.77} \mathrm{O}_{9.48}\right)$ appears at $2 \theta$ of $10.1^{\circ}, 15.8^{\circ}$, and $43.2^{\circ}$, 
and an unnamed zeolite phase $\left(\mathrm{Na}_{1.96} \mathrm{Al}_{2} \mathrm{Si}_{6.84} \mathrm{O}_{17.66}\right)$ appears. It is speculated that the aluminosilicate component in fly ash has been effectively recombined. In the process of the alkali fusion-hydrothermal method, the crystal structure in fly ash is destroyed, and the silicon-aluminum component forms an aluminosilicate gel, which crystallizes to form different zeolite structures. This means that after alkali fusionhydrothermal treatment, a new type of zeolite with a high cation exchange capacity containing multiple crystal phases is synthesized.
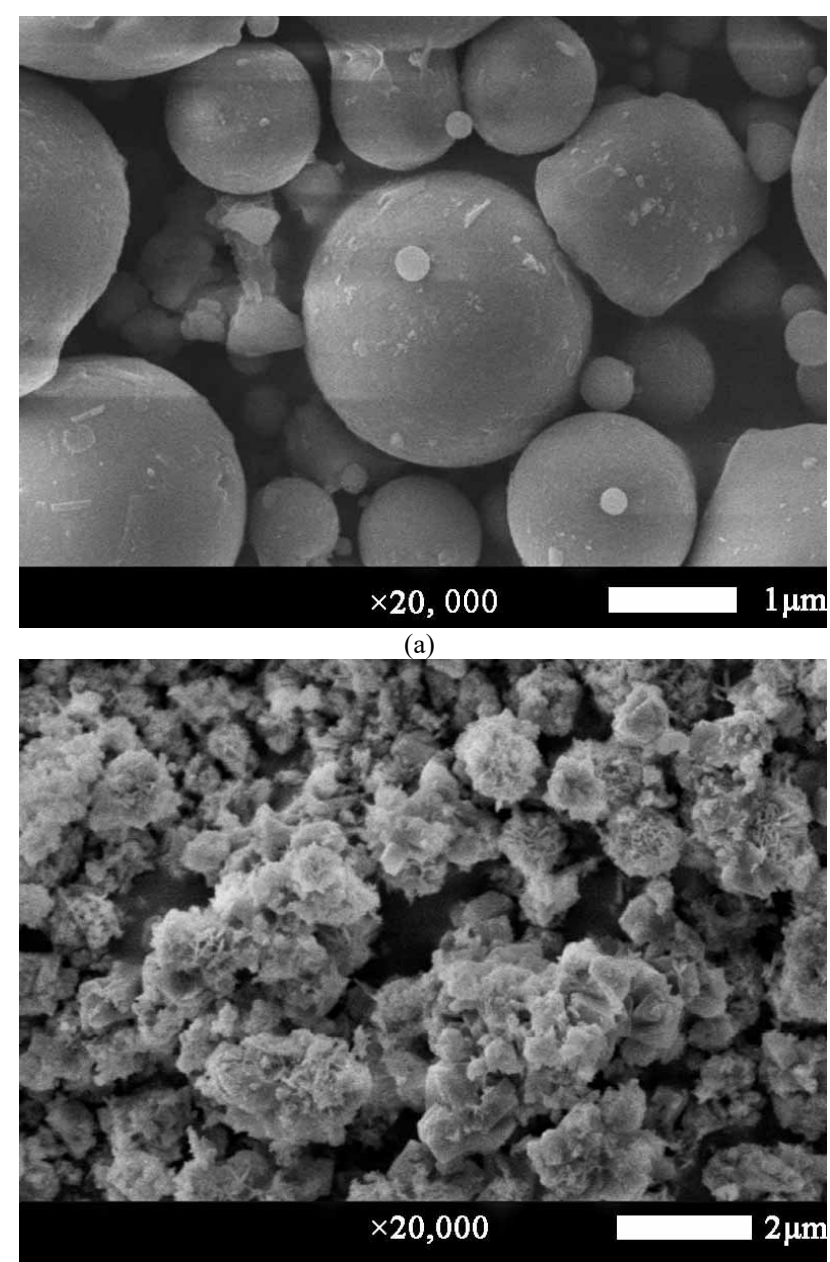

(b)

Fig.2. SEM of fly ash(a) and its synthetic zeolite(b) $(\times 20,000$ times $)$

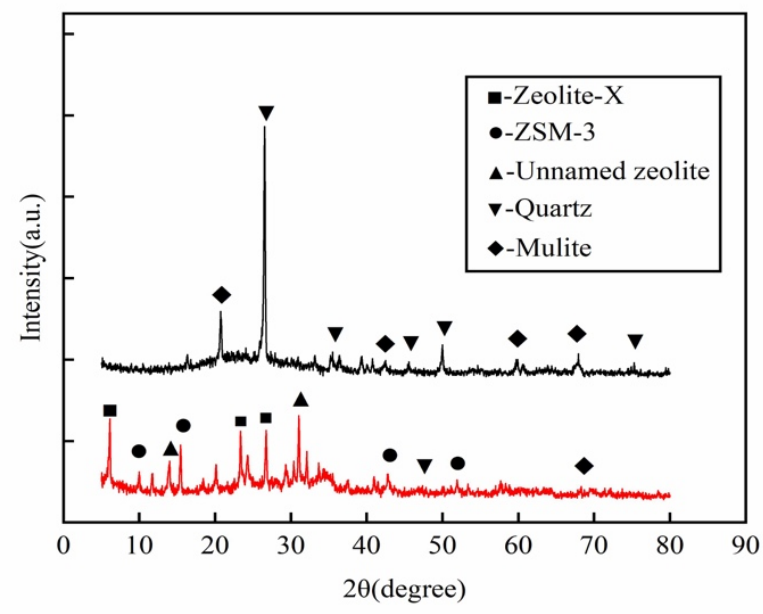

Fig.3. XRD patterns of fly ash and its synthetic zeolite

(3) Specimens design and preparation
Based on a large number of preliminary experiments, the basic experimental conditions were controlled as follows: the amount of agent $\mathrm{CaS}_{5}$ was 3 times of the molar number of $\mathrm{Cr}$ (VI) reduced to $\mathrm{Cr}$ (III), zeolite contents were $15 \%$, cement contents were $20 \%, \mathrm{Cr}$ (VI) concentrations were $3000 \mathrm{mg} / \mathrm{kg}$ and total chromium concentrations were $6500 \mathrm{mg} / \mathrm{kg}$. One of the parameters, such as the synthetic zeolite contents $(0 \%, 5 \%, 10 \%, 15 \%$, and $20 \%)$, the cement contents $(5 \%, 10 \%, 15 \%$, and $25 \%)$, or the $\mathrm{Cr}$ (VI) concentrations $(1000,3000$, and $5000 \mathrm{mg} / \mathrm{kg}$ ) and $\mathrm{Cr}$ (III) concentrations of 7/6 times the $\mathrm{Cr}$ (VI) concentrations, were changed during the preparation of the standard specimens, and the influence of various factors on the freeze-thaw cycles stability was analyzed.

Adding reducing agent $\mathrm{CaS}_{5}$ to contaminated soil, its contents were 3 times of the $\mathrm{Cr}$ (VI) contents, and the water contents were $22 \%$ (weight ratio) of contaminated soil. The mixture was mixed and stirred for $30 \mathrm{~min}$. Then, synthetic zeolite and water were added, and the water contents were $22 \%$ (weight ratio) of synthetic zeolite. The mixture was mixed and stirred for $30 \mathrm{~min}$. Finally, cement and water were added, and the water contents were $22 \%$ (weight ratio) of cement. The mixture was stirred for $10 \mathrm{~min}$ to obtain the repaired contaminated soil. The repaired contaminated soil was made into standard specimens (diameter of $50 \mathrm{~mm}$ and height of $100 \mathrm{~mm}$ ) by the static pressure method, and the specimens were placed into a sealed plastic bag and labeled. The specimens were subsequently placed in a standard curing room (temperature $20 \pm 2{ }^{\circ} \mathrm{C}$ and relative humidity $\geq$ $95 \%$ ) for $28 \mathrm{~d}$, and the freeze-thaw cycles tests were finally performed.

\subsection{Test and measurement methods \\ (1) Freeze-thaw cycles tests}

After the contaminated soil had been cured for $28 \mathrm{~d}$, the DX40-290 low-temperature test box was used for indoor freeze-thaw tests. With reference to the temperature change of seasonal frozen soil area, the freeze-thaw temperature was determined to be $-20 \sim 20{ }^{\circ} \mathrm{C}$. To prevent moisture loss of the specimens during the freeze-thaw process, each specimen was sealed with an inner bag and placed in the freeze-thaw box. During freezing, the temperature of the freezer was maintained at a constant temperature of $-20{ }^{\circ} \mathrm{C}$ for $12 \mathrm{~h}$. During melting, the curing cabinet was maintained at a constant temperature of $20{ }^{\circ} \mathrm{C}$ for $12 \mathrm{~h}$. This process was regarded as one freeze-thaw cycle. The UCS measurement and the toxicity leaching tests were carried out after 16 freeze-thaw cycles.

\section{(2) Determination of the UCS}

ASTM D2166-06 was used as the reference standard to test the UCS of the specimens, and the axial strain rate was 1 $\mathrm{mm} / \mathrm{min}$. The solidified chromium-contaminated soil can be used as roadbed fillings. To facilitate long-term safety and stability, the UCS of the soil after remediation needs to reach $10 \mathrm{MPa}$.

\section{(3) Determination of the leaching concentrations}

The leaching tests were carried out according to Chinese standard 'Solid waste-extraction procedure for leaching toxicity-horizontal vibration method' (HJ/T 557-2010), and the leaching concentrations of $\mathrm{Cr}(\mathrm{VI})$ and total chromium were measured by Z-2000 atomic absorption spectrophotometer. The leaching concentrations complied with the 'Environmental protection technical specifications for pollution treatment of the chromium residue' (HJ/T 301- 
2007) with $\mathrm{Cr}$ (VI) leaching concentrations of $\leq 0.5 \mathrm{mg} / \mathrm{L}$ and total chromium leaching concentrations of $\leq 1.5 \mathrm{mg} / \mathrm{L}$.

\section{(4) Microscopic analysis}

Scanning electron microscope (JEOL JSM-7500F) was used to observe the surface morphology of the specimens during the freeze-thaw cycles, and X-ray diffractometer (Shimadzu XRD-6100) was used to analyze the mineral composition of the specimens during the freeze-thaw cycles.

\section{Result analysis and discussion}

\subsection{Analysis of the strength characteristics}

Figs. 4(a), (b), and (c) describe the variation in the UCS as the number of freeze-thaw cycles increases under different cement contents, zeolite contents and pollutant concentrations. Figs. 4(a), (b), and (c) show that the UCS of the specimens made of contaminated soil after remediation has similar trend as the number of freeze-thaw cycles increases. The UCS of the specimens increases slightly in the early period of the freeze-thaw cycles and then gradually decreases. Because of the insoluble precipitate of hydroxide produced by the reaction covering the surface, the cement is not fully in contact with water, which delays the hydration reaction of the cement, and the strength of the solidified contaminated soil increases slightly in the early period of freeze-thaw cycles. During freeze-thaw cycles, as the ice crystals in the pores grow and expand in volume, the surrounding soil particles are squeezed, making the soil particles shift or even break and deform. At the same time, the shape of the pores can also change, and the structure of the soil is weakened significantly, resulting in a decrease in the UCS $[25,29]$. Although the freeze-thaw crushing effects also exist in the early period of the cycles, the effects on the UCS in the early period are not significant compared to the hydration effects. In addition, the UCS increases slightly after 4 freeze-thaw cycles, the rate of decrease in UCS begins to increase, and it stabilizes after 12-14 cycles. Because of the phase change and migration of water inside the specimens at this time, a stable water migration path is gradually formed [30]. Overall, the freeze-thaw cycles have few effects on the UCS of the specimens, indicating that the chromium-contaminated soil after remediation has a good resistance to freeze-thaw loss.

During the experiment, when $5 \%$ cements were added, the specimens were very fragile. After 28 days of curing, the specimen did not have enough UCS, and it was seriously damaged after 1 freeze-thaw cycle, so its specific UCS could not be obtained. When the cement contents were $10 \%$ or above, the specimens had sufficient UCS, so the starting point of the cement contents in the experiment was $10 \%$. Fig. 4(a) shows that the UCS corresponding to different cement contents $(10 \%, 15 \%, 20 \%$ and $25 \%)$ before freeze-thaw cycles is $1.26,4.94,11.04$ and $12.05 \mathrm{MPa}$, respectively. After 16 freeze-thaw cycles, compared with the initial value, the UCS decreases by $0.87,0.71,0.49$, and $0.46 \mathrm{MPa}$, respectively. It can be seen that the increase in the cement contents can affect the UCS of the specimens after freezethaw cycles. The higher the cement contents are, the smaller the strength decreases. Under the same number of cycles, the specimens with higher cement contents have higher UCS, indicating that the increase of the cement contents can increase the degree of cementation between the particles in the specimens, reduce the pores between the particles, and increase the integrity of the specimens, which is beneficial to improve the resistance of the specimens to freeze-thaw cycles damage [31]. With the progression of the hydration reaction, some gels (CSHs, CAHs) continue to develop, so that the pores of the soil continue to decrease and the density continues to increase [32], leading the UCS of the solidified contaminated soil to increase with increasing cement contents. Fig. 4(a) also shows that when the cement contents increase to $20 \%$, the UCS of the contaminated soil after remediation reaches more than $10 \mathrm{MPa}$, which meets the strength requirement of more than $10 \mathrm{MPa}$ for a roadbed filling material.

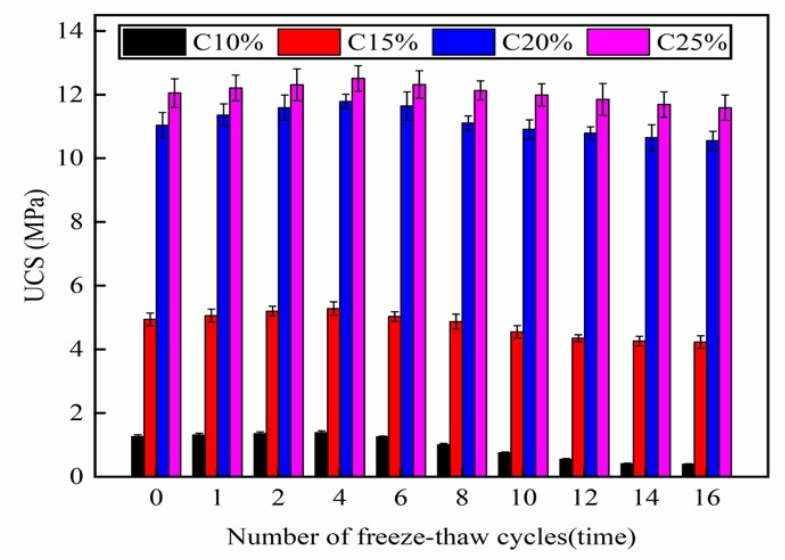

(a)

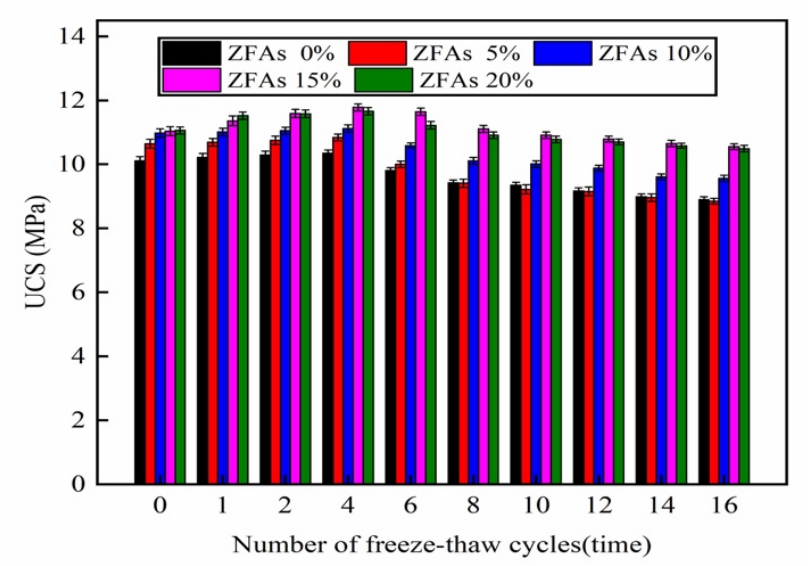

(b)

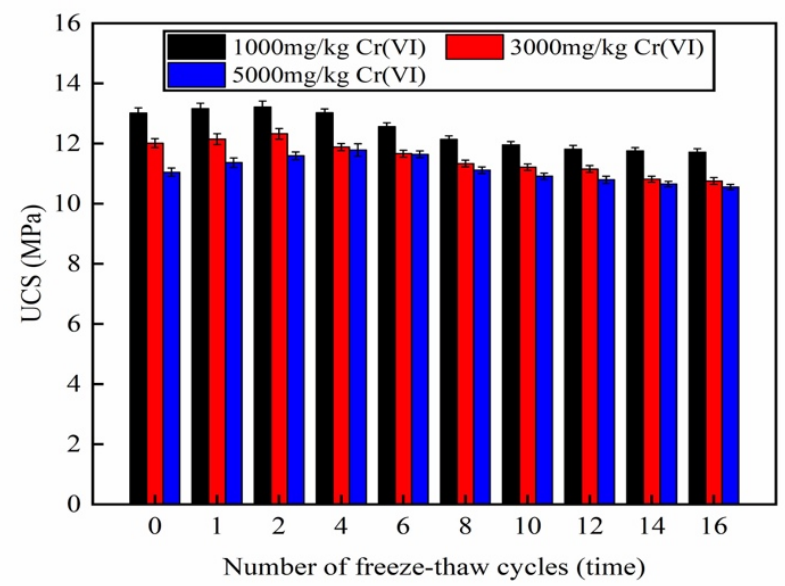

(c)

Fig.4. Variation curve of the UCS with increasing freeze-thaw cycles under different conditions. (a) Different cement contents (b) Different zeolite contents. (c) Different pollutants concentrations

Note: C and ZFAs represent cement and synthetic zeolite from fly ash, respectively; the percentage value represents the percentage of dry soil mass. 
Fig. 4(b) shows that in the absence of freeze-thaw cycles, when the zeolite contents increase to $15 \%$, the UCS of the repaired chromium-contaminated soil increases by $9.4 \%$ compared with that without the synthetic zeolite, which presents a small increase. When the contents increase to $20 \%$, the UCS increases by $0.2 \%$ compared with the contents of $15 \%$, and the change is not obvious. Moreover, the specimens also exhibit similar changes after undergoing freeze-thaw cycles, indicating that the appropriate addition of synthetic zeolite is also beneficial for increasing the UCS of the chromium-contaminated soil after remediation, but the effects are not significant. The cement provides $\mathrm{Ca}(\mathrm{OH})_{2}$ component that can stimulate the activity of synthetic zeolite from fly ash. The active oxides in the glass phase of the synthetic zeolite react with water to form CAH and $\mathrm{CSH}$ gels, enveloping the particles and filling the pores, resulting in a slight increase in UCS [31].

Fig. 4(c) shows that under the same number of freezethaw cycles, the lower the chromium concentrations are, the higher the UCS is, indicating that the presence of heavy metal ions reduces the UCS of the contaminated soil after remediation. On the one hand, chromium ions react to form hydroxides and alkaline double salt precipitates, which adhere to the surface of cement particles, block them from contacting water, and inhibit the hydration reaction of cement and the production of colloids such as $\mathrm{CSH}$ and $\mathrm{CAH}$. The higher the chromium concentrations are, the stronger the inhibition effects are. The soil porosity increases, forming a sedimentary rock-like honeycomb structure that further expands into the pores, and these pores are difficult to recover. With the continuous loss of water from the inside, the UCS of the specimens eventually decreases. On the other hand, chromium ions dissolve the cementing salt between the soil particles, which leads to strength loss [25]. For the specimens with lower concentrations (1000 and $3000 \mathrm{mg} / \mathrm{kg}$ ), the maximum UCS is got after 2 freeze-thaw cycles. While for high concentrations $(5000 \mathrm{mg} / \mathrm{kg})$, the maximum UCS is reached after 4 freeze-thaw cycles, which shows that the higher concentrations of chromium have stronger delaying effects on cement hydration. After 16 freeze-thaw cycles, the strength loss rates of different concentrations of contaminated soil are 9.9\% (1000 mg/kg), 10.5\% (3000 $\mathrm{mg} / \mathrm{kg})$, and $19.9 \%(5000 \mathrm{mg} / \mathrm{kg})$, and the strength loss is within $20 \%$, which reflects good water stability.

\subsection{Analysis of leaching characteristics}

Figs. 5(a), (b) and (c) show the variation in the leaching concentrations of $\mathrm{Cr}$ (VI) and total chromium after remediation as the number of freeze-thaw cycles increases under different zeolite contents, cement contents and initial chromium concentrations. Figs. 5(a), (b), and (c) show that the toxic leaching of specimens is basically the same as the influence of the number of freeze-thaw cycles. The leaching concentrations of $\mathrm{Cr}(\mathrm{VI})$ and total chromium decrease after 1 freeze-thaw cycle. Because at the beginning of the freezethaw cycles, the physical and chemical interactions between the cement hydrate, synthetic zeolite and soil are still ongoing. Their adsorption of chromium ions and the formation of hydroxide precipitation in an alkaline environment can satisfy the requirements of solidification/ stabilization of chromium ions, making the leaching of chromium ions difficult. Afterwards, the leaching concentrations gradually increase with the increase in the number of freeze-thaw cycles, indicating that the freezethaw cycles reduce the holding capacity of composite preparation to chromium ions. With the progression of the freeze-thaw cycles reaction, freeze-thaw erosion weakens the cementation degree between the contaminated soil particles and hydration products, destroys the skeleton structure in the solidified body and increases the number of pores and the effective passage of water through the solidified body, increasing the risk of chromium dissolution.

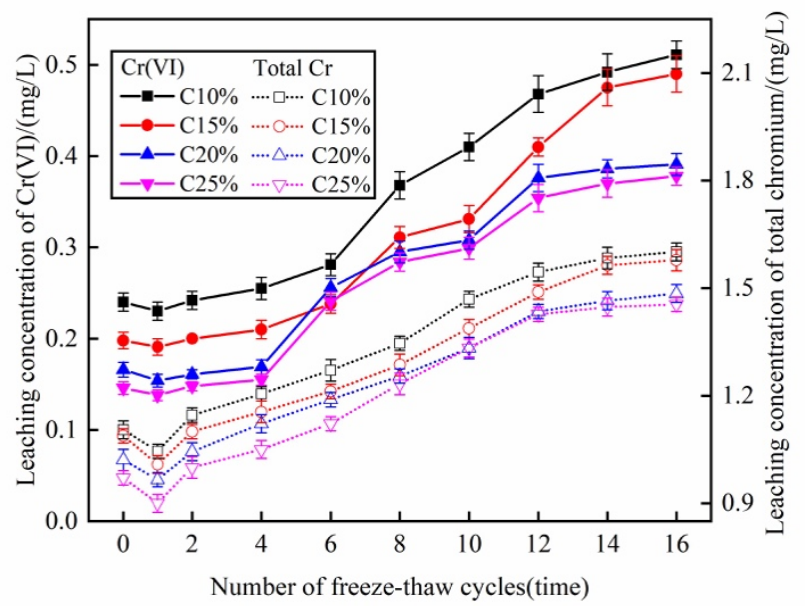

(a)

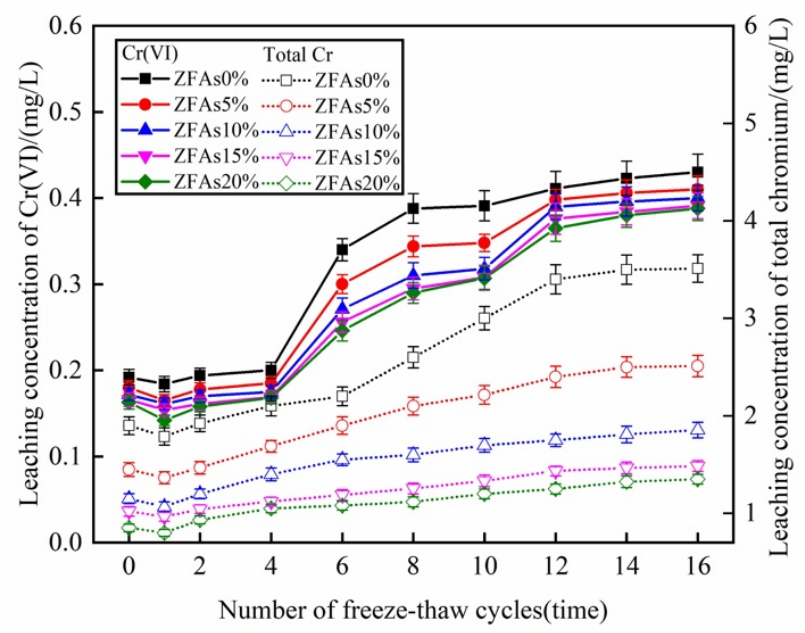

(b)

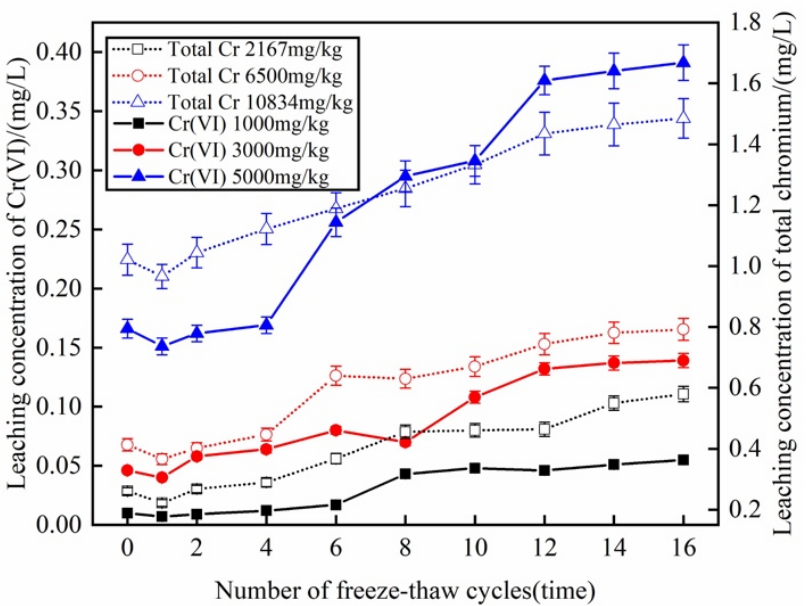

(c)

Fig. 5. Trend of leaching changes under the action of freeze-thaw cycles (a) Different cement contents. (b) Different zeolite contents. (c) Different pollutants concentrations

Fig. 5(a) shows that under the same number of freezethaw cycles, 3 times the calcium polysulfide contents, and $15 \%$ of the synthetic zeolite contents, as the cement contents increase, chromium ions are fixed through the solidification of cement so that the leaching concentrations of total 
chromium and $\mathrm{Cr}$ (VI) decrease. Thus, the higher the cement contents are, the better the ability of the repaired chromiumcontaminated soil to resist freeze-thaw damage is, which can weaken the effects of the freeze-thaw cycles on the leaching concentrations of pollutants.

According to Fig. 5(b), under the conditions of 3 times the calcium polysulfide contents and $20 \%$ of the cement contents, the increase of the zeolite contents has few effects on the leaching concentrations of Cr (VI). Therefore, zeolite has no adsorption effects for $\mathrm{Cr}$ (VI). However, as the zeolite contents increase, total chromium leaching concentrations decrease significantly. And the increase in zeolite contents weakens the influence of freeze-thaw cycles on the toxicity associated with total chromium leaching. Because the total chromium concentrations are the sum of the $\mathrm{Cr}$ (III) and $\mathrm{Cr}$ (VI) concentrations, synthetic zeolite can adsorb a large amount of $\mathrm{Cr}$ (III) in contaminated soil through physical and chemical actions such as ion exchange and electrostatic attraction, resulting in the decrease in the total chromium leaching concentrations. In addition, when synthetic zeolite is not added, during the entire freeze-thaw cycles, the leaching concentrations of $\mathrm{Cr}$ (VI) can always be kept below $0.5 \mathrm{mg} / \mathrm{L}$ due to the reduction effects of calcium polysulfide and the solidified effects of cement, which meets the requirements of the specification for the toxic leaching of $\mathrm{Cr}$ (VI). However, the amount of $\mathrm{Cr}$ (III) in soil increases greatly, including not only originally existing in the contaminated soil, but also converted from $\mathrm{Cr}$ (VI) by reduction. Therefore, the solidified effects of cement alone cannot achieve the desired effects, resulting in the total chromium leaching concentrations to be greater than the specification requirements, so it is meaningful to add zeolite. When the zeolite contents reach $15 \%$, the total chromium leaching concentrations are kept below $1.5 \mathrm{mg} / \mathrm{L}$ during the entire freeze-thaw cycles, meeting the specification requirements. Therefore, in practical applications, zeolite contents of $15 \%$ are appropriate.

Fig. 5(c) shows that the leaching concentrations of $\mathrm{Cr}$ (VI) and total chromium under different freeze-thaw cycles increase with increasing initial chromium concentrations. For specimens with different initial chromium concentrations, at the 1st freeze-thaw cycle, the $\mathrm{Cr}$ (VI) and the total chromium concentrations both decrease. After 2 freezethaw cycles, they begin to increase. Compared with the initial concentrations, at the 16th freeze-thaw cycle, the leaching concentrations of $\mathrm{Cr}(\mathrm{VI})$ and total chromium both increase, and the high-concentrations chromiumcontaminated soil not only has a large leaching concentrations, but also a large fluctuation range. These results show that freeze-thaw cycles reduce the solidification ability of the solidified soil with chromium, increase the leaching risk of heavy metal pollutants in the soil, and reduce the long-term stability of the soil. In particular, freeze-thaw cycles have a greater impact on the fixation capacity of chromium in high-concentrations chromiumcontaminated soil than that in low chromium concentrations. According to the freeze-thaw test results, the leaching concentrations of $\mathrm{Cr}$ (VI) and total chromium in soils with different chromium concentrations have not exceed the 'Identification Standard for Hazardous Wastes' (GB 5085.32007). This indicates that the $\mathrm{Cr}$ (VI) and total chromium of the chromium-contaminated soil after remediation can maintain relative stability for a long time in a lowtemperature environment, and the solidified soil has good resistance to freeze-thaw cycles, especially the lowconcentrations chromium-contaminated soil.

\subsection{Microanalysis}

\section{(1) SEM analysis}

Fig. 6 shows the SEM images of the chromiumcontaminated soil after the combined remediation after 0,2 , 8 , and 16 freeze-thaw cycles.

Before the 1st freeze-thaw cycle (standard specimens), some pores are observed in the SEM image of the specimens, and there are platy crystals on the surface, which can prevent the cement from contacting moisture and affect the hydration process. However, at the 2 nd cycle, the pores of the specimens slightly reduce, the soil particles are cemented together, and the structural integrity of the specimens improves significantly. Because the small broken particles produced by the freeze-thaw cycles and hydration fill the pores, making the soil structure more compact. This is consistent with the change of the UCS in the above mentioned test process, indicating that the presence of chromium slows the hydration reaction, so that the UCS is effectively improved to a certain extent. After 8 freeze-thaw cycles, the surface structure becomes rough, and a large number of coral-like substances and some needle-like crystals appear. Due to the tensile damage during the process of frost heave, some wafers at the frost front of the contaminated soil are broken, and the UCS of the specimens reduces. The pores around the ice crystals can relieve part of the frost heave force [31], resulting in fewer fractures in the specimens and no obvious expansion or cracking. After 16 freeze-thaw cycles, a large number of pores and cracks appear in the specimens, and the fractured roughness is obvious. The fractured part of the hydrated crystal forms a weak surface and a clear layered structure. And the internal structure of the specimens changes significantly. These changes reduce the durability of chromium-contaminated soil after remediation.
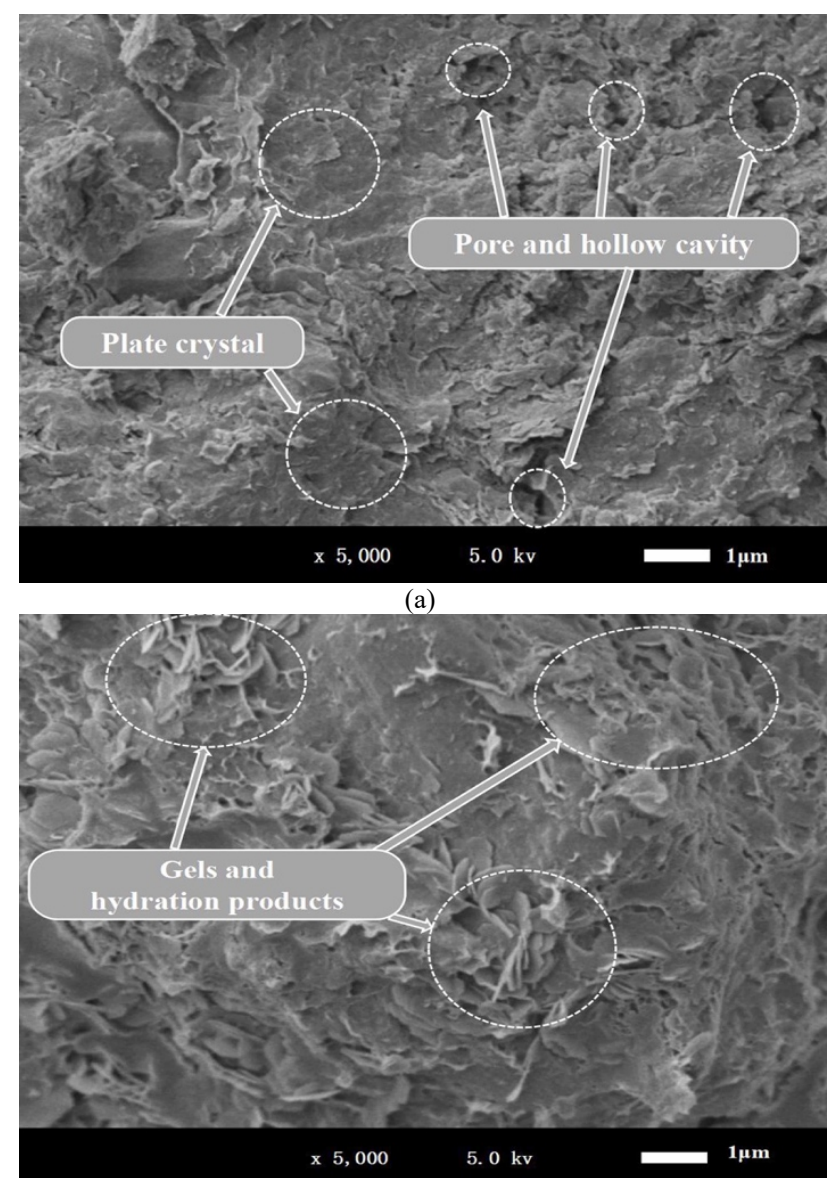

(b) 

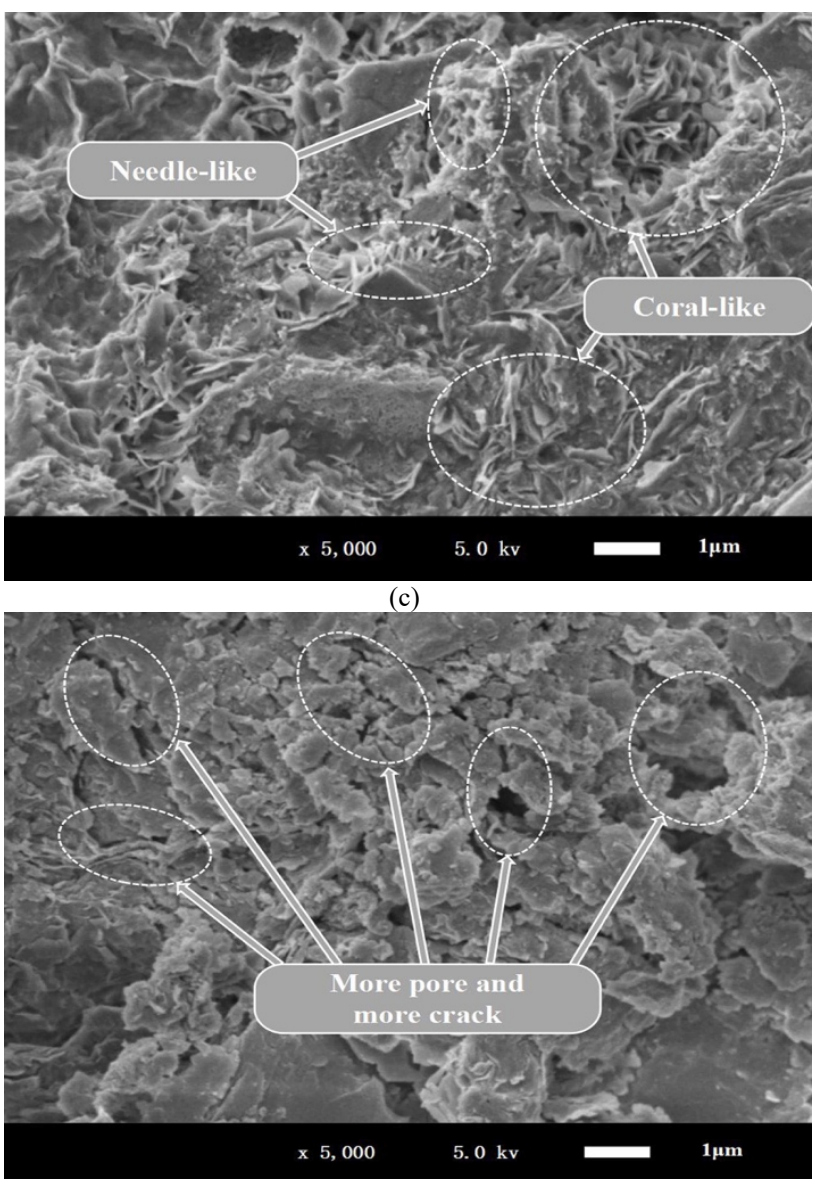

(d)

Fig. 6. SEM images of chromium-contaminated soil under different freeze-thaw cycles.(a) 0 cycle. (b) 2 cycles. (c) 8 cycles. (d) 16 cycles

\section{(2) XRD analysis}

Fig. 7 shows the XRD patterns of the specimens repaired by the composite preparation after $0,2,8$ and 16 freeze-thaw cycles. The presence of $\mathrm{SiO}_{2}, \mathrm{CSH}, \mathrm{CAH}, \mathrm{Ca}(\mathrm{OH})_{2}, \mathrm{Al}_{2} \mathrm{O}_{3}$, $\mathrm{CaCO}_{3}$, and stilbite is observed from the XRD pattern before the 1st freeze-thaw cycle. Among them, the peaks observed at $2 \theta$ of $29.5^{\circ}$ and $67.8^{\circ}$ confirm the presence of hydroxides, which are wrapped on the surface of the cement, hindering the contact between the cement and water, and slowing the hydration reaction. After 2 freeze-thaw cycles, the contents of $\mathrm{SiO}_{2}$ and $\mathrm{Al}_{2} \mathrm{O}_{3}$ decrease slightly, while the contents of $\mathrm{CSH}, \mathrm{CAH}, \mathrm{Ca}(\mathrm{OH})_{2}$ and $\mathrm{CaCO}_{3}$ increase significantly. This indicates that the hydration reaction continues at this time, and more hydration products are produced to cause the soil particles to be tightly combined. So the destructive effects of the freeze-thaw cycles on the specimens are alleviated and the UCS of the specimens is effectively improved. At the same time, during the hydration reaction process, the internal specific surface area of the specimens increases substantially due to the extension of fibrous calcium silicate hydrates. The chromium ions are adsorbed or produce hydroxide precipitates, which fill the pores of the soil so that the chromium concentrations are reduced. The difference between the XRD patterns after 8 freeze-thaw cycles, before the 1st freeze-thaw cycle, and after 2 freeze-thaw cycles is mainly reflected in the contents of hydration products such as CAH and CSH. The XRD pattern after 8 freeze-thaw cycles shows that the contents of hydration products decrease. Under repeated freeze-thaw action, the state of the moisture in the pores continuously changes. The density field, the moisture field, and the stress field of soil particles are redistributed [29]. The soil skeleton is structurally transferred, and the stability of the soil aggregates is destroyed. The physical and chemical properties are significantly changed. So the leaching risk of chromium ion is increased and the UCS is decreased significantly. After 16 freeze-thaw cycles, a large amount of fibrous $\mathrm{CSH}$ disappears at the $2 \theta$ of $50.1^{\circ}$. The water in the pores undergoes phase change and migration, causing the soil to produce reciprocating frost heave and thaw settlement, which gradually leads to the destruction of the soil. This reciprocating frost heave and thaw settlement continue to act, constantly change the connection between the pore structure and solid particles in the soil, resulting in greater changes in the soil structure. These changes reduce the strength and durability of the specimen, and cause chromium ions to dissolve from the soil.

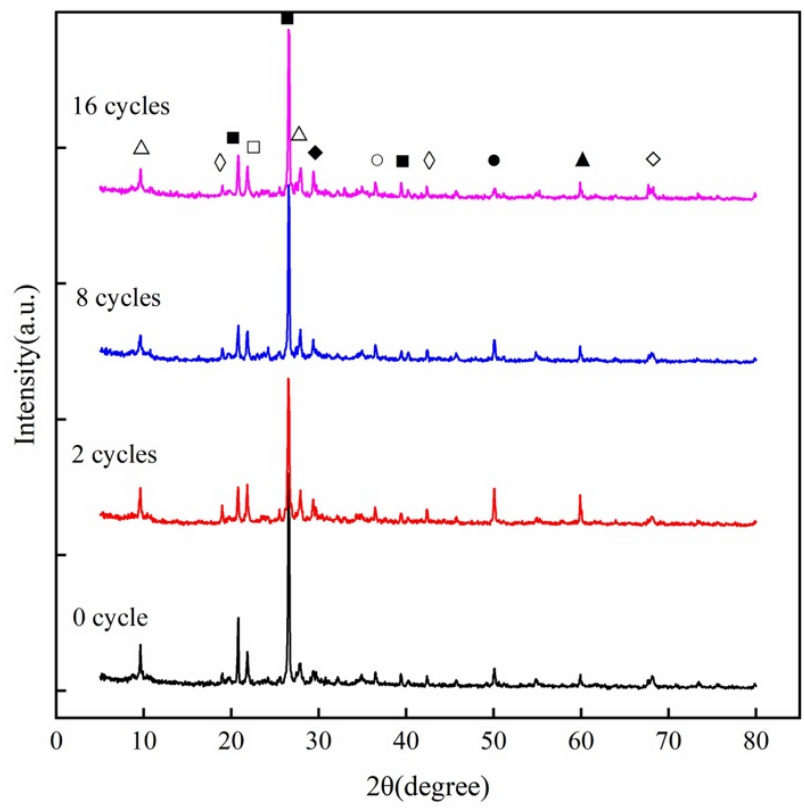

Fig. 7. XRD pattern of chromium-contaminated soil under different freeze-thaw cycles. $\mathbf{a}-\mathrm{SiO}_{2}$. $\bullet-\mathrm{CSH}$. $\Delta-\mathrm{CAH} . \bullet-\mathrm{Ca}(\mathrm{OH})_{2} . \diamond-\mathrm{Cr}(\mathrm{OH})_{3}$. $\diamond-\mathrm{Al}(\mathrm{OH})_{3} \cdot \Delta$-Stilbite. $\square-\mathrm{Al}_{2} \mathrm{O}_{3} \cdot$ ०- $\mathrm{CaCO}_{3}$

\section{Conclusions}

To resolve the problem of poor long-term stability of highly toxic chromium-contaminated soil, freeze-thaw cycles stability tests were carried out for chromium-contaminated soil after the combined remediation of a composite composed (calcium polysulfide, synthetic zeolite and cement). The effects of different cement contents, zeolite contents, initial $\mathrm{Cr}$ (VI) concentrations and freeze-thaw cycles on the UCS and toxic leaching stability of contaminated soil after remediation were studied, and the following conclusions were obtained:

(1) Combined reduction-solidification/stabilization remediation was performed to chromium-contaminated soil containing high concentrations of highly toxic $\mathrm{Cr}$ (VI) and $\mathrm{Cr}$ (III), employing calcium polysulfide as the reducing agent, synthetic zeolite from fly ash as the adsorbent, and cement as the curing agent. The repaired contaminated soil does not exceed the standard strength and leaching 
concentrations requirements during multiple freeze-thaw cycles, showing good freeze-thaw cycles resistance.

(2) The increase of the cement contents effectively weakens the influence of freeze-thaw cycles on the stability of chromium-contaminated soil, which improves the UCS of chromium-contaminated soil after remediation and reduces the leaching of chromium ions. However, it cannot meet the total chromium leaching requirement in high-concentrations chromium-contaminated soil. Moreover, the synthetic zeolite from fly ash stabilizes $\mathrm{Cr}$ (III) through a series of physical and chemical effects. The increase of the zeolite contents reduce the leaching concentrations of total chromium, but have few effects on the UCS and toxicity of Cr (VI) leaching.

(3) Freeze-thaw cycles reduce the chromium solidification ability of the solidified soil and increase the risk of heavy-metal contamination. The higher the chromium concentrations in the contaminated soil are, the stronger the delay effects on cement hydration are, and the more obvious the weakening effects on the UCS of the solidified body are. The action decreases the UCS and increases the leaching concentrations of $\mathrm{Cr}$ (VI) and total chromium of the solidified body.

(4) The UCS and toxic leaching of solidified chromiumcontaminated soil are followed nearly the same trend as the number of freeze-thaw cycles increases. That is, in the initial freeze-thaw cycles, the UCS of solidified contaminated soil increases slightly, while the toxic leaching decreases slightly. When the number of freeze-thaw cycles continues to increase, its UCS decreases gradually, and toxic leaching increases gradually.

(5) During freeze-thaw cycles, the micro-structure changes of chromium-contaminated soil after remediation are consistent with the micro-mechanical strength and toxin- leaching changes. The UCS and leaching concentrations of the chromium-contaminated soil are the result of the combined effects of the hydration reaction of the compound preparation and the freeze-thaw cycles.

In summary, the combined remediation method of a composite preparation (calcium polysulfide-synthetic zeolite from fly ash-cement) proposed in this study can maintain the long-term stability of UCS and leaching under the freezethaw cycles. The repaired contaminated soil can be used as roadbed fillings or building materials. It provides a good foundation for the engineering application of chromium contaminated soil after remediation. However, due to the complexity of extreme climate, the field application includes not only freeze-thaw, but also complex environmental effects such as dry-wet, carbonation, erosion of groundwater containing salt, so there may be some deviation between the research and the practice. Therefore, in the future research, the comprehensive effects of complex environment should be considered, which can provide more help for the practical application of engineering.

\section{Acknowledgements}

The authors are grateful for the support provided by the National Key Research and Development Program of China (2017YFC1503106), Liaoning Provincial Natural Science Foundation of China (No. 2019-ZD-0037), and Liaoning BaiQianWan Talents Program (Grant No. 2018C01).

This is an Open Access article distributed under the terms of the Creative Commons Attribution License.

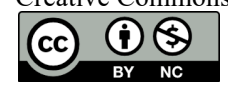

\section{References}

1. Goodarzi, A. R., Movahedrad, M., "Stabilization/solidification of zinc-contaminated kaolin clay using ground granulated blastfurnace slag and different types of activators". Applied Geochemistry, 81, 2017, pp.155-165.

2. Samborska, A., Stepniewska, Z., Stepniewski, W., "Influence of different oxidation states of chromium(VI,III) on soil urease activity". Geoderma, 122(2-4), 2004, pp. 317-322.

3. Li, X., Fan, M., Liu, L., Chang, J., Zhang, J., "Treatment of highconcentration chromium-containing wastewater by sulfate-reducing bacteria acclimated with ethanol”. Water Science \& Technology, 80(12), 2019, pp.2362-2372.

4. Li, J., Chen, L., Zhan, B., Wang, L., Poon, C. S., Tsang, D. C. W., "Sustainable stabilization/solidification of arsenic-containing soil by blast slag and cement blends". Chemosphere, 271(10), 2021, pp. 129868.

5. Mulligan, C. N., Yong, R. N., Gibbs, B. F., "Remediation technologies for metal-contaminated soils and groundwater: an evaluation". Engineering Geology, 60(1-4), 2001, pp.193-207.

6. Reginatto, C., Cecchin, I., Heineck, K. S., Thomé, A., Reddy, K. R., "Use of nanoscale zero-valent iron for remediation of clayey soil contaminated with hexavalent chromium: batch and column tests". International Journal of Environmental Research and Public Health, 17(3), 2020, pp.1001.

7. Li, Q., Zhang, L., Ji, W., Chang, Z., Chong, R., Li, D., Li, J., "Feasibility of using ammonium iron(II) sulfate to passivate hexavalent chromium in polluted soil". Environmental Technology,11, 2020, pp.1-21.

8. Zha, F., Zhu, F., Kang, B., Xu, L., Chu, C., "Experimental investigation of cement/soda residue for solidification/stabilization of Cr-contaminated soils". Advances in Civil Engineering, 1, 2020, pp.1-13.

9. Dahlawi, S. M., Siddiqui, S., "Calcium polysulphide, its applications and emerging risk of environmental pollution-a review article". Environmental Science and Pollution Research, 24(1), 2017, pp. 92-102.
10. Li, X., Liu, L., Liu, H., Wang, L., "Combined remediation method of chromium contaminated soil”. China, ZL201711444 739.1. 2017-12-27.

11. Wang, F., Zhang, Y., Shen, Z., Pan, H., Xu, J., Al-Tabbaa, A., "GMCs stabilized/solidified $\mathrm{Pb} / \mathrm{Zn}$ contaminated soil under different curing temperature: leachability and durability". Environmental Science and Pollution Research, 26, 2019, pp.26963-26971.

12. Wang, L., Cho, D., Tsang, T. C. W., Cao, X., Hou, D., Shen, Z., Alessi, D. S., Ok, Y. S., Poon, C. S., "Green remediation of As and $\mathrm{Pb}$ contaminated soil using cement-free clay based stabilization/ solidification”. Environment International, 126, 2019, pp.336-345.

13. Wang, X., Li, Y., Mao, N., Zhou, Y., Guo, P., "The adsorption behavior of $\mathrm{Pb}^{2+}$ and $\mathrm{Cd}^{2+}$ in the treated black soils with different freeze-thaw frequencies". Water Air \& Soil Pollution, 228, 2017, pp.193-201.

14. Janoo, V. C., Firicano, A. J., Barna, L. A., Orchino, S. A., "Field testing of stabilized soil". Journal of Cold Regions Engineering, 13, 1999, pp.37-53.

15. Shihata, S. A., Baghdadi, Z. A., "Simplified method to assess freeze-thaw durability of soil cement". Journal of Materials in Civil Engineering, 13, 2001, pp.243-247.

16. Yarbasi, N., Kalkan, E., Akbulut, S., "Modification of the geotechnical properties, as influenced by freeze-thaw, of granular soils with waste additives". Cold Regions Science and Technology, 48(1), 2007, pp.44-54.

17. Tiwari, N., Satyam, N., Singh, K., "Effect of curing on microphysical performance of polypropylene fiber reinforced and silica fume stabilized expansive soil under freezing thawing cycles". Scientific Reports, 10(1), 2020, pp.7624.

18. Muhannad, I., Fathi, S., "Effectiveness of lime in stabilising subgrade soils subjected to freeze-thaw cycles". Advances in Materials Science and Engineering, 21(1), 2020, pp.42-60. 
19. Baldovino, J., Izzo, R. L., Rose, J. L., "Effects of freeze-thaw cycles and porosity/cement index on durability, strength and capillary rise of a stabilized silty soil under optimal compaction conditions". Geotechnical and Geological Engineering, 39, 2021, pp.481-498.

20. Aydin, K., Sivrikaya, O., Uysal, F., "Effects of curing time and freeze-thaw cycle on strength of soils with high plasticity stabilized by waste marble powder". Journal of Material Cycles and Waste Management, 22, 2020, pp.1459-1474.

21. Mukiza, E., Zhang, L., Liu, X., "Durability and microstructure analysis of the road base material prepared from red mud and flue gas desulfurization fly ash". International Journal of Minerals Metallurgy and Materials, 27(4), 2020, pp. 555-568.

22. Azarsa, P., Gupta, R., "Freeze-thaw performance characterization and leachability of potassium-based geopolymer goncrete". Journal of Composites Science, 4(2), 2020, pp.45.

23. Yang, Z., Li, D., Deng, R., Tian, X., Ren, S., “An experimental study for influence of freeze-thaw cycles on strength and pore characteristics of solidified lead-contaminated soil". Journal of Engineering Geology, 27(03), 2019, pp.539-549.

24. Li, J., Wang, P., Zhang, T., Li, Z., Xue, Q., "Effect of freeze-thaw cycle on engineering properties and microstructure of stabilized/ solidified lead contaminated soil treated by cement". Chinese Journal of Geotechnical Engineering, 38(11), 2016, pp.2043-2050.

25. Zhou, J., Chen, L., Tang, Q., Chen, G., Pan, L., Chen, S., "Stressstrain properties of heavy metal contaminated soils stabilized/solidified by cement under cyclic freezing-thawing". Journal of Nanjing Tech University(Natural Science Edition), 40(03), 2018, p.81-87.
26. Wei, M., Wu, H., Du, Y., Xia, W., "Experimental study of zn and $\mathrm{pb}$ contaminated soils stabilized with new phosphate-based binder under freeze-thaw cycles". Rock and Soil Mechanics, 36(S1), 2015, pp.215-219.

27. Liu, J., Zha, F., Xu, L., Kang, B., Yang, C., Feng, Q., Zhang, W., Zhang, J., "Strength and microstructure characteristics of cementsoda residue solidified/stabilized zinc contaminated soil subjected to freezing-thawing cycles".Cold Regions Science and Technology, 172, 2020, pp.102992.

28. Yang, R., Lian, H., Li, X., Cai, L., "Experimental study on mechanical properties and leaching characteristics of solidification/ stabilization heavy metal contaminated soil". Science Technology and Engineering, 20(16), 2020, pp.6672- 6677.

29. Liu, J., Zha, F., Xu, L., Kang, B., Yang, C., Zhang, W., Zhang, J., Liu, Z., "Zinc leachability in contaminated soil stabilized/solidified by cement-soda residue under freeze-thaw cycles". Applied Clay Science, 186, 2020, pp.105474.

30. Hou, S., Zhang, H., Yang, Z., Zhang, Y., Zhang, Y., Ding, Z., "Study on freeze-thaw stability of $\mathrm{Cu}$-contaminated soil solidified by magnesium phosphate cement". Chinese Journal of Rock Mechanics and Engineering, 39(S1), 2020, pp.3123-3129.

31. Yang, Z., Li, X., Li, D., Wang, Y., Liu, X., "Effects of long-term repeated freeze-thaw cycles on the engineering properties of compound solidified/stabilized $\mathrm{Pb}$-contaminated soil: deterioration characteristics and mechanisms". International Journal of Environmental Research and Public Health, 17(5), 2020, pp.1798.

32. Zha, F., Xu, L., Cui, K. R., "Strength characteristics of heavy metal contaminated soils stabilized/solidified by cement". Rock and Soil Mechanics, 33(03), 2012, pp.652-656+664. 